\title{
Caudate nucleus and relearning of delayed alternations in cats
}

\author{
IVAN DIVAC \\ Laboratory of Behavioral Physiology, Institute of Neurophysiology \\ University of Copenhagen, Copenhagen, Denmark
}

\begin{abstract}
Earlier studies demonstrated that lesions in the anterior part of the caudate nucleus impair delayed response-type behavior when made in intact cats, but not if made in cats which learned delayed responses after ablation of the prefrontal cortex. The present experiment tested the hypothesis th: ' " anterior part of the caudate nucleus, if not necessary once the task has been relearned, may be invc. in the process of relearning of delayed alternation. The results showed that cats with lesions in both the prefrontal cortex and the caudate nucleus were able to relearn the task and were not more impaired than the cats with ablations of the prefontal cortex alone. Thus, the anterior part of the caudate nucleus in cats seems to subserve delayed response-type tasks only as long as the prefrontal cortex and mediodorsal thalamic nucleus are preserved.
\end{abstract}

A large body of evidence indicates that lesions in the part of the caudate nucleus which receives projections from the prefrontal cortex produce the same effects as the ablation of the prefrontal cortex (for reviews, see Divac, 1972a; Rosvold, 1968). It has been inferred that the prefrontal cortex and the associated part of the caudate nucleus participate in mediation of the same behaviors. The relation between the two formations is not clear, but can be conveniently studied in cats which, although impaired, can master delayed response-type tasks after ablations of the prefrontal cortex (Divac, 1972b; Warren, 1964; Wikmark \& Divac, 1974; Wikmark \& Warren, 1972).

The anterior part of the caudate nucleus in cats receives projections from the prefrontal cortex (Webster, 1965). Lesions in this caudate region impaired preoperatively acquired delayed responses (Divac, 1968) and delayed alternation (Divac, 1972b) in cats with an intact frontal cortex. However, Wikmark and Divac (1973) found that cats which learned delayed responses after ablation of the prefrontal cortex were unaffected by subsequent destruction of the anterior part of the caudate nucleus, indicating that this formation plays a role in delayed response-type tasks only while connected to the prefrontal cortex.

The present study investigated the possibility that the caudate nucleus is involved in the process of relearning of delayed alternation in prefrontal cats. Two questions were asked: (1) Can cats with combined prefrontal and caudate lesions be retrained on delayed alternation? (2) If so, is their reacquisition slower than in cats with damage restricted to the prefrontal cortex?

\section{METHOD}

\section{Subjects}

Eight adult cats of both sexes were brought from private homes into the laboratory 2 months before the experiment began and were caged individually. Water was always available in the home cages. Daily food rations sufficient to keep the cats' body weights at about $90 \%$ of the ad lib value were given once a day, $2 \mathrm{~h}$ after training. Four cats received bilateral ablations of prefrontal cortex; in the other four cats, lesions were made in both the caudate nucleus and the prefrontal cortex.

\section{Apparatus}

The animals were trained in the Nencki testing situation (Fig. 1).

\section{Procedure}

The procedure for testing cats on delayed alternation in the Nencki testing situation has been described in detail elsewhere (Divac, 1972b). Briefly, the cats were first shaped to approach either of the feeders upon release from the sliding cage and to return to the center of the apparatus after consuming a reward consisting of mixed fish cream, minced canned cat food, and water. Then 30 trials, including corrections, of 5-sec delayed alternation were given daily for 5 days a week. The day after reaching criterion of less than 11 errors in 10 blocks of 10 trials, all cats were sham operated and tested for retention 20 days later. Two cats made more than 10 errors in this retention test and were retrained, again sham operated, and tested once again after 20 days. In this second test, both cats performed proficiently. The day following proficient "preoperative" retention test, each cat received either another sham operation $(\mathrm{N}=4)$ or the caudate lesion $(\mathrm{N}=4)$. Ten days later, all cats underwent ablation of the prefrontal cortex. After a further 10 days, the cats were retrained to the original criterion.

\section{Surgery}

The cats, anesthetized with $36 \mathrm{mg} / \mathrm{kg}$ pentobarbital, injected intraperitoneally, were operated under sterile conditions. The gyrus proreus and the lateral wall of the presylvian sulcus were removed by suction. Caudate lesions were produced by direct current of $2.5 \mathrm{~mA}$ passed from a tungsten electrode $0.4 \mathrm{~mm}$ in diam, bare $1.5 \mathrm{~mm}$ at the tip, to a skin retractor. The

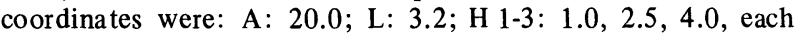
point for $30 \mathrm{sec} ; \mathrm{A}: 19.0 ; \mathrm{L}: 3.3 ; \mathrm{H} \mathrm{1-3}: 1.0,2.5,4.0 ; \mathrm{A}: 18.0$;

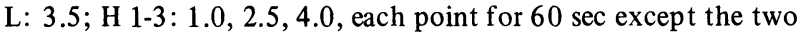
points at 4.0 , where the current lasted for only $30 \mathrm{sec}$. In sham operations only the skin was cut. After each operation, the cats were given daily 100,000 units of penicillin for 3 days.

\section{Histology}

The cats were transcardially perfused in deep anesthesia with saline and $10 \%$ Formalin. The brains were removed, hardened in Formalin for several days, photographed, and imbedded in 


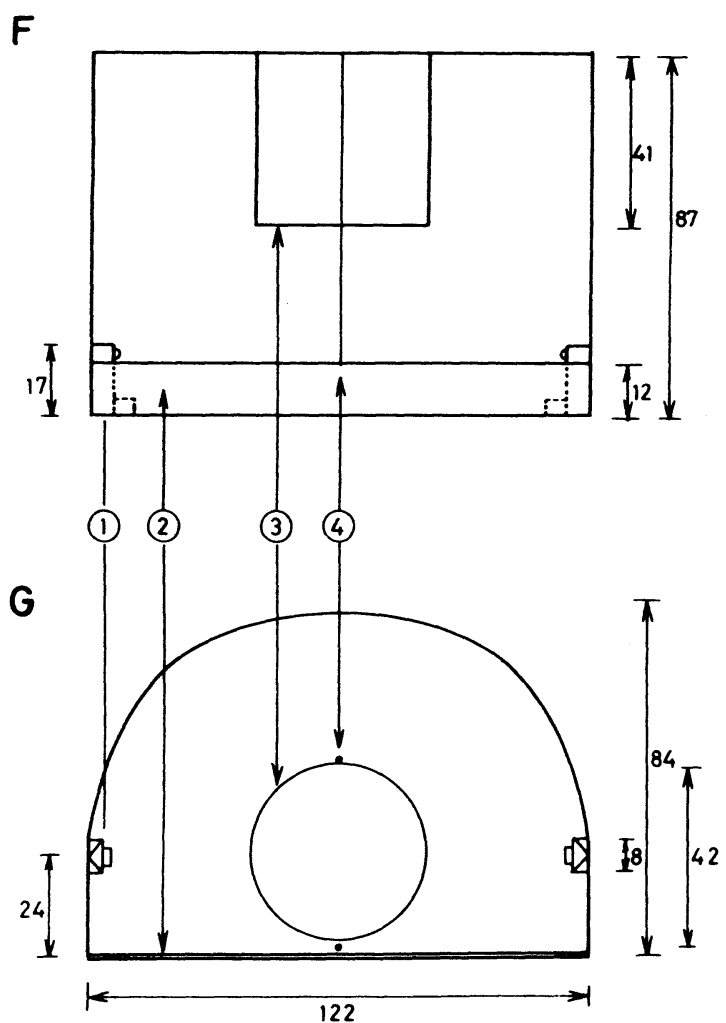

Fig. 1. Nencki testing situation. (F) Front view and (G) ground plan. (1) Food dispenser and stimulus source; (2) wooden barrier; (3) wire-net sliding cage; (4) guiding rods. Dimensions in centimeters.

gelatine. The brains were cut frozen at 100 microns. Every fifth section was mounted, covered, and drawn from a projected picture.

\section{RESULTS}

\section{Anatomy}

Cortical ablations varied little and were not systematically different between the two groups, either in extent or in position. Similar cortical lesions produced almost complete retrograde degeneration of the mediodorsal thalamic nucleus to the level of the habenulopeduncular fasciculus posteriorly (Divac, 1973). The caudate lesions were localized in the area which receives projections from the prefrontal cortex (Webster, 1965) and were uniform in size. The lesions of the most impaired animal in each group are illustrated in Fig. 2; these two lesions were not the largest in the respective groups.

\section{Behavior}

All cats in the present study showed a clear impairment after lesions in the prefrontal system (third column in Table 1). The increase in errors was significant for both groups: $p<.01$ for the prefrontal and $p=$ .0107 for the prefrontal and caudate group ( $t$ test for correlated measures). Some cats were able to relearn rapidly in spite of extensive lesions in the prefrontal cortex, or the prefrontal cortex and the anterior part of the caudate nucleus. It is obvious from Table 1 that the groups did not differ significantly either in the number of errors made in the first 100 trials postoperatively (third column in Table 1) or in the number of trials and errors required for relearning (fourth column in Table 1).

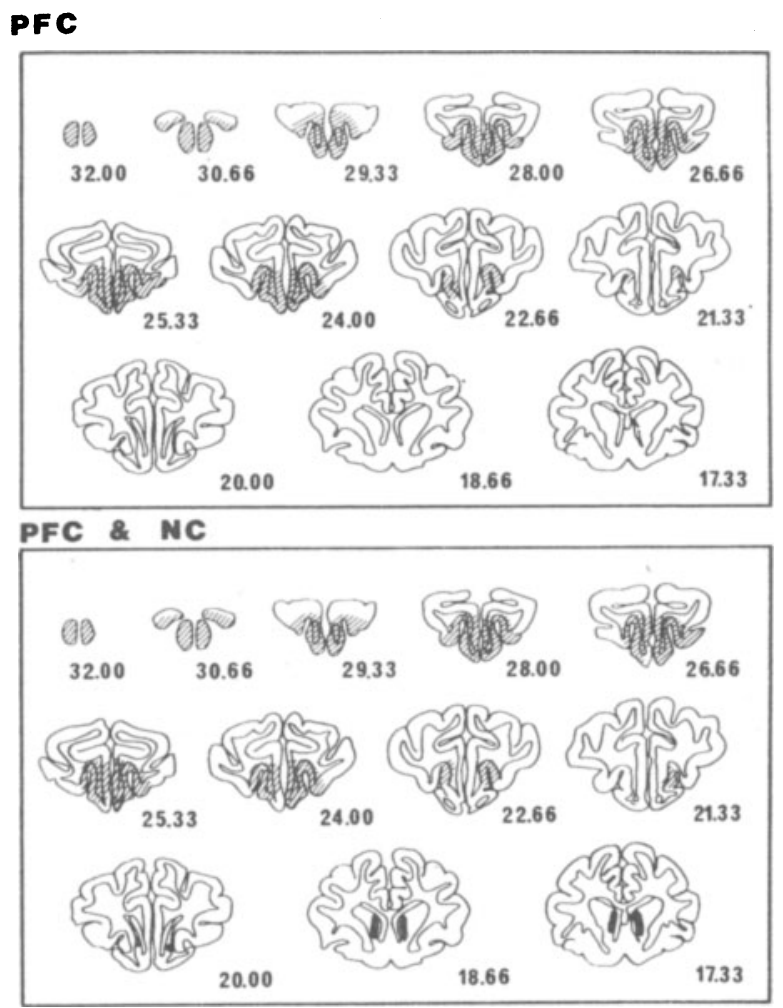

Fig. 2. Lesions in cats $(N=4)$ from each group. PFC: prefrontal cortex; NC: caudate nucleus. Cortical ablations striped, caudate lesions stippled. Numbers denote distance in millimeters from the interaural line.

Table 1

\begin{tabular}{|c|c|c|c|c|c|c|}
\hline & \multicolumn{2}{|c|}{$\begin{array}{c}\text { Preoperative } \\
\text { Learning }+\end{array}$} & \multicolumn{2}{|c|}{$\begin{array}{c}\text { Errors in } 100 \\
\text { Trials of } \\
\text { Retention }\end{array}$} & \multicolumn{2}{|c|}{$\begin{array}{c}\text { Postoperative } \\
\text { Relearning + } \\
\end{array}$} \\
\hline & \multirow{2}{*}{ Trials } & \multirow{2}{*}{$\begin{array}{c}\text { Er- } \\
\text { rors }\end{array}$} & Dre & Dos & Trialc & Errore \\
\hline & & & Fre & Post & IIIals & L11015 \\
\hline \multicolumn{7}{|c|}{ Prefrontal } \\
\hline 1 & 160 & 37 & 5 & 17 & 40 & 11 \\
\hline 2 & 100 & 26 & 8 & 22 & 60 & 16 \\
\hline $3 *$ & 330 & 79 & 2 & 32 & 1040 & 294 \\
\hline 4 & 200 & 52 & 8 & 55 & 1130 & 378 \\
\hline \multicolumn{7}{|c|}{ Prefrontal and Caudate } \\
\hline 1 & 510 & 84 & 3 & 15 & 50 & 14 \\
\hline 2 & 310 & 80 & 8 & 49 & 410 & 144 \\
\hline $3 *$ & 170 & 54 & 10 & 60 & 470 & 203 \\
\hline 4 & 230 & 56 & 10 & 45 & 1010 & 365 \\
\hline
\end{tabular}

Note-Pre $=$ preoperative, post $=$ postoperative .

*Animals which required "preoperative" retraining. + Exclusive of 100 criterion trials. 


\section{DISCUSSION}

The main finding of the present experiment was that adding a lesion in the anterior part of the caudate nucleus to the prefrontal ablation did not prevent cats from relearning delayed alternation. Moreover, these cats were not more impaired than the cats which received only prefrontal ablations. Thus, the anterior part of the caudate nucleus is not necessary, and appears not even to be facilitatory, for relearning of delayed alternation in cats without the prefrontal cortex. Which structures mediate delayed alternation in the absence of the prefrontal cortex, the associated region of the caudate nucleus, and the mediodorsal thalamic nucleus, remains to be found.

The great variability of postoperative performance in the present cats does not affect the main finding. It may, however, obscure a subtle group difference. This variability is a common phenomenon in studies with prefrontal cats (Divac, 1968, 1972b, 1973; Warren, 1964; Warren, Warren, \& Akert, 1962, 1972; Wikmark \& Warren, 1972), and itself deserves attention.

In accordance with an earlier experiment (Wikmark \& Divac, 1974), the present study suggests that the participation of the anterior part of the caudate nucleus in mediation of delayed response-type behavior in cats may depend on input from the prefrontal cortex, the mediodorsal thalamic nucleus, or both.

Another interpretation of the present finding is that the anterior caudate lesions produced delayed response-type impairment in the cats with no previous brain damage (Divac, 1968, 1972b) by interruption of pathways connecting the prefrontal cortex with other parts of the brain. Although this possibility has not been excluded, some evidence obtained in monkeys and rats renders it unlikely. That the caudate nucleus plays a role in delayed responding and alternation in monkeys is indicated by the activity of single cells during the performance (Fuster \& Alexander, 1971; Niki et al, 1972), and by the deficit produced by caudate lesions at an age when prefrontal ablations have no effect (Goldman \& Rosvold, 1972; Kling \& Tucker, 1967). Furthermore, adult monkeys were not impaired by lesions confined to the white matter close to the caudate nucleus unless the subcallosal fasciculus was bilaterally damaged (Divac et al, 1967; Rosvold \& Delgado, 1956).
In rats which relearned delayed alternation after large anterior and medial cortical ablations, lesions in the caudate nucleus severely impaired the performance (Wikmark \& Divac, 1973, and in preparation).

\section{REFERENCES}

Divac, I. Effects of prefrontal and caudate lesions on delayed response in cats. Acta Biologiae Experimentalis (Warsaw), $1968,28,149-167$.

Divac, I. Neostriatum and functions of prefrontal cortex. Acta Neurobiologiae Experimentalis, 1972a, 32, 461-477.

Divac, I. Delayed alternation in cats with lesions of the prefrontal cortex and the caudate nucleus. Physiology \& Behavior, 1972b, 8, 519-522.

Divac, I. Delayed response in cats after frontal lesions extending beyond the gyrus proreus. Physiology \& Behavior, 1973, 10, 717-720.

Divac, I., Rosvold, H. E., \& Szwarcbart, M. K. Behavioral effects of selective ablation of the caudate nucleus. Journal of Comparative \& Physiological Psychology, 1967,63, 184-190.

Fuster, J. M., \& Alexander, G. E. Neuron activity related to short-term mem ory. Science, 1971, 173, 652-654.

Goldman, P. S., \& Rosvold, H. E. The effects of selective caudate lesions in infant and juvenile rhesus monkeys. Brain Research, $1972,43,53-66$

Kling, A., \& Tucker, T. J. Effects of combined lesions of frontal granular cortex and caudate nucleus in the neonatal monkey. Brain Research, 1967, 6, 428-439.

Niki, H., Sakai, M., \& Kubota, K. Delayed alternation performance and unit activity of the caudate head and medial orbitofrontal gyrus in the monkey. Brain Research, 1972, 38 , 343-353.

Rosvold, H. E. The prefrontal cortex and caudate nucleus: A system for effecting correction in response mechanisms. In $\mathbf{C}$. Rupp (Ed.), Mind as a tissue. New York: Hoeber, 1968.

Rosvold, H. E., \& Delgado, J. M. R. The effect on delayed alternation performance of stimulating or destroying electrically structures within the frontal lobes of the monkey brain. Journal of Comparative \& Physiological Psychology, $1956,49,365-372$.

Warren, J. M. The behavior of carnivores and primates with lesions in the prefrontal cortex. In J. M. Warren and K. Akert (Eds.), The frontal granular cortex and behavior. New York: McGraw-Hill, 1964.

Warren, J. M., Warren, H. B., \& Akert, K. Orbitofrontal cortical lesions and learning in cats. Journal of Comparative Neurology, 1962, 118, 17-41.

Warren, J. M., Warren, H. B., \& Akert, K. The behavior of chronic cats with lesions in the frontal association cortex. Acta Neurobiologiae Experimentalis, 1972, 32, 361-392.

Webster, K. E. The cortico-striatal projection in the cat. Journal of Anatomy, 1965, 99, 329-337.

Wikmark, R. G. E., \& Divac, I. Comparative studies of functional relations in the frontal lobes. Paper presented at the 81 st Annual Convention of the American Psychological Association, Montreal, 1973.

Wikmark, R. G. E., \& Divac, I. Absence of effect of caudate lesions on delayed responses acquired after large frontal ablations in cats. Israel Journal of Medical Sciences, 1974, in press.

Wikmark, R. G. E., \& Warren, J. M. Delayed response learning by cage-reared normal and prefrontal cats. Psychonomic Science, $1972,26,243-245$.

(Received for publication November 1, 1973; revision received January 14,1974 .) 